\title{
CONTRATOS UTILIZADOS NA EXPLORAÇÃO DE TERRAS RURAIS PARA A GERAÇÃO DE ENERGIA FOTOVOLTAICA
}

\author{
Ana Clara Amaral Arantes Boczar ${ }^{1}$ \\ Frederico de Andrade Gabrich ${ }^{2}$
}

RESUMO: Com fundamento no método hipotético-dedutivo, tendo como marco teórico o disposto na Constituição, Código Civil e nas Leis no 4.504/1964, 5.709/1971, 6.015/1973, $8.245 / 91,8.935 / 1994$, esta pesquisa visa apresentar estratégias jurídicas para resposta ao seguinte problema: qual é o melhor modelo contratual para estabelecer vínculo entre proprietários de terras rurais e as pessoas jurídicas interessadas na instalação das usinas de geração de energia fotovoltaica? O problema da pesquisa é relevante pela ausência de regulação específica, bem como porque não há um entendimento pacífico sobre quais contratos podem ou não ser levados a registro ou averbação na matrícula do imóvel.

Palavras-chave: energia fotovoltaica; terras rurais; contratos; estratégia jurídica, segurança jurídica.

\section{CONTRACTS USED IN THE EXPLORATION OF RURAL LAND FOR THE GENERATION OF PHOTOVOLTAIC ENERGY}

\begin{abstract}
Based on the hypothetical-deductive method, having as a theoretical framework the provisions of the Constitution, Civil Code and Laws n. 4.504/1964, $5.709 / 1971,6.015 / 1973,8.245 / 1991,8.935 / 1994$, this research aims to present legal strategies for answer to the following problem: what is the best contractual model to establish a link between rural landowners and legal entities interested in installing photovoltaic power plants? The research problem is relevant due to the lack of specific regulation, as well as because there is no peaceful understanding about which contracts can or cannot be registered in the property's registration.
\end{abstract}

Keywords: Photovoltaics; rural land; contracts; legal strategy, legal certainty.

\section{INTRODUÇÃO}

\footnotetext{
1 Mestranda em Direito Privado pela Universidade FUMEC, pós-graduada em Direito Notarial e Registral pela parceria do INDIC - Instituto Nacional de Direito e Cultura com o CEDIN - Centro de Direito e Negócios, pós-graduada em Direito Privado pela Universidade Cândido Mendes, Graduada em Direito na Faculdade Milton Campos. Coautora do livro "Usucapião Extrajudicial, questões notariais e tributárias", coautora do livro "Registro Civil das Pessoas Naturais, Temas Aprofundados", da editora JusPodivm. Advogada, é membro da Comissão da OAB de Direito Notarial e Registral e atua na área cível nas esferas judicial e extrajudicial. Lattes: http://lattes.cnpq.br/0542795723640084. Endereço postal: Rua Alvarenga Peixoto, nº 300, ap 502, Lourdes, Belo Horizonte/MG. CEP 30.180-120. E-mail: anaclaraboczar@ gmail.com

${ }^{2}$ Doutor, mestre e especialista em Direito Empresarial/Comercial pela Universidade Federal de Minas Gerais UFMG. Professor Adjunto da Universidade FUMEC. Consultor de inovação e estrategista jurídico. Endereço postal: Rua Bambuí, 355/402, Bairro Cruzeiro, Belo Horizonte/MG. CEP 30.310-320 E-mail: frederico.gabrich@gmail.com.
} 
A geração de energia solar teve início no Brasil somente no ano de 2011, sendo uma atividade recente e em pleno crescimento. $\mathrm{O}$ alto potencial energético do país tem atraído muitos investimentos para o setor.

No entanto, o rápido desenvolvimento dessa atividade não foi acompanhado pelas normas que a regulam, especialmente no que diz respeito aos contratos firmados entre as pessoas jurídicas geradoras de energia elétrica e os proprietários das terras rurais usadas para a instalação das usinas geradoras de energia fotovoltaica.

A produção de energia fotovoltaica pode ser realizada, basicamente, de duas maneiras. A primeira, chamada de geração distribuída, na qual o consumidor instala as placas solares em sua propriedade para gerar sua própria energia. A segunda, centralizada, na qual usinas de grande porte são instaladas em grandes áreas rurais para a geração, transmissão e posterior distribuição da energia.

É na geração centralizada de energia que se discutem quais contratos podem e devem ser celebrados entre as pessoas jurídicas e os proprietários das terras rurais usadas para a instalação das usinas de geração de energia fotovoltaica, visando garantir a necessária segurança jurídica do investimento realizado no projeto.

Com fundamento no método hipotético-dedutivo, tendo como marco teórico o disposto na Constituição, Código Civil e nas Leis no 4.504/1964, 5.709/1971, 6.015/1973, 8.245/91, 8.935/1994, esta pesquisa visa, então, apresentar estratégias jurídicas para resposta ao seguinte problema: qual é o melhor modelo contratual para estabelecer vínculo entre proprietários de terras rurais e as pessoas jurídicas interessadas na instalação das usinas de geração de energia fotovoltaica?

O problema da pesquisa é relevante pela ausência de regulação específica, bem como porque não há um entendimento pacífico sobre quais contratos podem ou não ser levados a registro ou averbação na matrícula do imóvel.

\section{A EXPLORAÇÃO DE TERRAS RURAIS PARA A GERAÇÃO DE ENERGIA SOLAR NO BRASIL}


A exploração de energia fotovoltaica é uma atividade que se iniciou há apenas 10 anos no Brasil e está em plena ascensão. A primeira usina de geração de energia solar foi instalada no ano de 2011 no sertão do Ceará (ÓRIGO, 2020).

Nada obstante, sendo o Brasil um país com dimensões continentais e com alto índice de incidência solar em parte significativa do seu território, possui um alto potencial energético para geração de energia solar e tem atraído muitos investimentos para o setor nos últimos anos.

Nesse sentido, o Instituto Nacional de Pesquisas Espaciais elaborou o Atlas Brasileiro de Energia Solar (BRASIL, 2017), no qual analisa o potencial energético do Brasil para geração de energia solar e apresenta diversos mapas que demonstram esse fato. Dentre eles, está o denominado "Total diário da irradiação direta normal” (PEREIRA, 2017, p.36), que demonstra a média anual de incidência de luz solar no país, sendo as áreas mais escuras aquelas com maior índice de irradiação, como se vê a seguir:

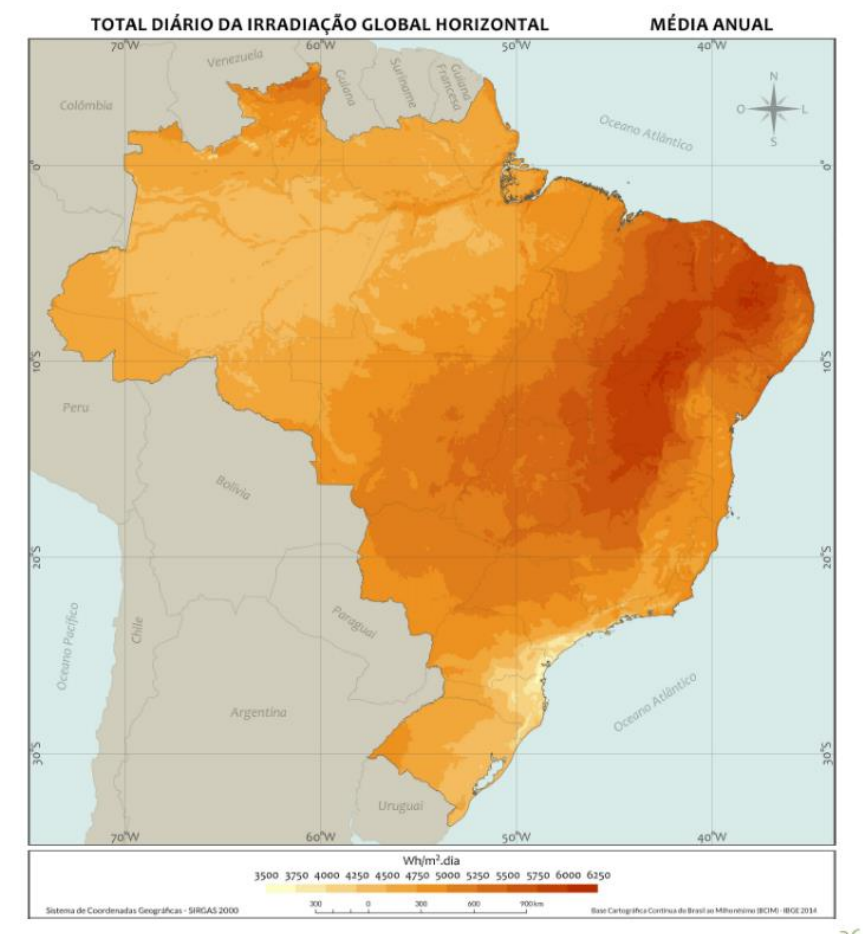

De fato, a produção de energia solar pressupõe três etapas principais: (i) geração; (ii) transmissão e (iii) distribuição. A etapa da geração, que mais interessa para o desenvolvimento desta pesquisa, pode ocorrer de forma centralizada ou distribuída (F. Ruy, 2019). 
A geração distribuída de energia é permitida no Brasil desde o ano de 2012, e regulamentada pela Resolução Normativa n 482 de 2012 (BRASIL, 2012), da Agência Nacional de Energia Elétrica (ANEEL). Nessa forma de geração, o consumidor - pessoa física ou jurídica - pode gerar sua própria energia e ainda fornecer eventual excedente para a rede de distribuição local dando origem a um crédito de energia. Com isso, quando for necessário consumir a energia da rede de distribuição, haverá a compensação daquele excedente (AGÊNCIA NACIONAL DE ENERGIA ELÉTRICA, 2015).

Por outro lado, a geração centralizada de energia é aquela feita por meio de usinas de grande porte que precisam ser instaladas em extensas áreas rurais para geração, transmissão e posterior distribuição. Para isso, geralmente é necessário que os “investidores" (concessionárias e permissionárias geradoras de energia elétrica) contratem o direito de uso e exploração de glebas rurais, para viabilizar a instalação das usinas geradoras de energia fotovoltaica. São exatamente esses contratos que são objeto de estudo do presente trabalho.

Realmente, os negócios jurídicos que envolvem imóveis devem ser levados a registro ou averbação na matrícula respectiva perante o Cartório de Registro de Imóveis competente, nos termos do artigo 167 da Lei $n^{\circ} 6.015$ de 1973 (BRASIL, 1973), para serem constituídos e/ou produzir seus efeitos perante terceiros e assim garantir a sua publicidade e a segurança jurídica.

O artigo 172 da Lei $n^{\circ}$ 6.015/73, prevê a competência dos Registros de Imóveis para a realização de registro ou averbação de determinados atos nos seguintes termos:

Art. 172 - No Registro de Imóveis serão feitos, nos termos desta Lei, o registro e a
averbação dos títulos ou atos constitutivos, declaratórios, translativos e extintos de
direitos reais sobre imóveis reconhecidos em lei, "inter vivos" ou "mortis causa"
quer para sua constituição, transferência e extinção, quer para sua validade em
relação a terceiros, quer para a sua disponibilidade. (BRASIL, 1973).

A Lei $n^{\circ} 8.935$ de 1994, que regulamenta os serviços notariais e de registro, dispõe em seu artigo $1^{\circ}$ que os "serviços notariais e de registro são os de organização técnica e administrativa destinados a garantir a publicidade, autenticidade, segurança e eficácia dos atos jurídicos”. (BRASIL, 1994).

Além disso, vale destacar que o Ofício de Registro de Imóveis também é regido pelo princípio da legalidade, pelo qual "somente poderá fazer aquilo que a lei autorizar, utilizandose dos princípios próprios do direito administrativo, uma vez que presta um serviço público" (GENTIL, 2020 p. 303.). Por isso, a atividade registral é plenamente vinculada e toda decisão 
sobre a registrabilidade ou não de algum título deve ser devidamente fundamentada (GENTIL, 2020, p. 303).

$\mathrm{Na}$ ausência de norma específica a ser seguida, o Oficial deverá decidir de forma fundamentada, com base no ordenamento jurídico vigente, mas ainda assim, haverá espaço para interpretações diversas para uma mesma situação, o que pode gerar insegurança jurídica.

No caso dos contratos firmados entre os "investidores" e os proprietários de terras rurais usadas para a instalação das usinas geradoras de energia fotovoltaica, não há regulamentação específica que esclareça quais instrumentos contratuais podem ser utilizados. Apesar de viger o princípio da autonomia da vontade nos contratos privados, ainda que condicionada "por normas de ordem pública em benefício do bem comum" (GAGLIANO, 2020), o tema merece ser regulamentado em razão da necessidade de inscrição desses contratos no Registro de Imóveis, como já explicitado.

Mas, com a falta de normas específicas, não há um entendimento pacífico entre os Oficiais de Registro de Imóveis sobre quais contratos podem ser utilizados para estabelecer o vínculo jurídico entre os "investidores" e os proprietários das terras rurais usadas para a implementação das usinas de geração de energia fotovoltaica e, consequentemente, quais deles podem ter ingresso na matrícula do imóvel.

$\mathrm{Na}$ prática, os investidores desses projetos geralmente evitam utilizar a compra e venda do imóvel no qual a usina será instalada, pois o custo da imobilização da terra acaba onerando demasiadamente o projeto. Daí a necessidade de se utilizar estrategicamente outros contratos, tais como, arrendamento, locação, direito real de superfície, dentre outros.

Diante da situação de incertezas e insegurança jurídica decorrente da falta de regulamentação específica, o Colégio Registral Imobiliário de Minas Gerais emitiu no ano de 2018 o parecer $\mathrm{n}^{\circ}$ 001/2018, com a finalidade de orientar os oficiais de Registro de Imóveis de Minas Gerais acerca dos contratos que podem ou não serem utilizados nos casos citados. Nesse parecer o Colégio analisa os contratos de locação, direito real de superfície, o arrendamento e a concessão ou cessão de uso. Na sua conclusão o mencionado parecer recomenda que somente a locação e o direito real de superfície sejam utilizados nesses casos. Mas uma análise mais detalhada desse entendimento, merece ser realizada, já que outras estratégias jurídicas também podem ser utilizadas para a viabilização dos investimentos realizados em projetos de geração de energia fotovoltaica. 
Feita uma breve contextualização do panorama no qual se enquadra a situação objeto de estudo, passa-se à análise dos contratos em espécie para, assim, verificar o cabimento ou não de cada um deles para a formalização da relação jurídica entre os "investidores" e os proprietários das terras rurais usadas para a implementação das usinas de geração de energia fotovoltaica.

\section{OS CONTRATOS UTILIZADOS ENTRE "INVESTIDORES" E PROPRIETÁRIOS DE TERRAS RURAIS}

\subsection{Contextualização prévia}

Inicialmente, antes de adentrar no estudo dos contratos em espécie, se faz necessário apresentar o contexto histórico e atual acerca dos contratos de compra e venda e de arrendamento de áreas rurais, geralmente firmados entre os proprietários de terras e as pessoas jurídicas que contam com sócio majoritário estrangeiro.

De fato, a Lei n. 5.709/71 regulamenta a aquisição de terras rurais por estrangeiros no Brasil, estabelece diversas restrições e prevê no seu $\S 1^{\circ}$, do art. $1^{\circ}$, que também se sujeitam a tais disposições "a pessoa jurídica brasileira da qual participem, a qualquer título, pessoas estrangeiras físicas ou jurídicas que tenham a maioria do seu capital social e residam ou tenham sede no Exterior”. (BRASIL, 1971).

Além disso, as restrições estabelecidas na Lei $n^{\circ}$ 5.709/71 se aplicam também ao arrendamento rural, por força do disposto no artigo 23 da Lei $\mathrm{n}^{\mathrm{o}} 8.629 / 93$, e devem ser observadas sob pena de nulidade do ato. ${ }^{3}$

Mas, com a promulgação da Constituição da República de 1988, passou-se a discutir se o $§ 1^{\circ}$, do art. $1^{\circ}$, da Lei $5.709 / 71$ foi ou não por ela recepcionado, uma vez que estabelece um regime diferenciado entre pessoas jurídicas brasileiras e pessoas jurídicas brasileiras que contam com sócios majoritários estrangeiros, aparentemente contrário às disposições constitucionais.

Com isso, a Advocacia Geral da União, baseada na sua competência de interpretação das normas e assessoramento ao Poder Executivo, prevista no artigo 131 da Constituição

\footnotetext{
3 Art. 15 - A aquisição de imóvel rural, que viole as prescrições desta Lei, é nula de pleno direito. O tabelião que lavrar a escritura e o oficial de registro que a transcrever responderão civilmente pelos danos que causarem aos contratantes, sem prejuízo da responsabilidade criminal por prevaricação ou falsidade ideológica. $\mathrm{O}$ alien ante está obrigado a restituir ao adquirente o preço do imóvel. (Art. 15 da Lei no $5.709 / 71$ )
} 
Federal de 1988, emitiu pareceres manifestando seu entendimento. Inicialmente, a Advocacia Geral da União entendeu pela não recepção do dispositivo ${ }^{4}$. Anos depois, a AGU alterou seu entendimento e editou novo parecer $^{5}$, passando a entender pela recepção do dispositivo e, consequentemente, pela aplicabilidade da lei $\mathrm{n}^{\circ} 5.709 / 71$ às pessoas jurídicas brasileiras que contam com sócios majoritários estrangeiros.

Mas essa mudança de entendimento pode ter afetado a validade dos contratos firmados antes do último parecer (em 2014), uma vez que, em matéria de direito notarial e registral, a inobservância das exigências legais enseja nulidade dos atos, nos termos do artigo 15 da Lei $n^{\circ} 5.709 / 71$.

Diante da insegurança jurídica decorrente das mudanças de entendimento que afetam diretamente os investimentos no setor de energia solar e do agronegócio, a Sociedade Rural Brasileira propôs a Ação de Descumprimento de Preceito Fundamental (ADPF) no 342, com o objetivo de pacificar o tema. Nessa ação, o STF deverá decidir acerca da recepção ou não do $\S 1^{\circ}$, do art. $1^{\circ}$ da Lei 5.709/71 pela Constituição da República de 1988. Essa ação segue em curso, não havendo decisão até o encerramento deste trabalho.

Além disso, foi proposto o projeto de lei no 2.963 de 2019, pelo Senador Irajá (PDS/TO), que visa regulamentar o artigo 190 da Constituição da República ${ }^{6}$, revogar a Lei ${ }^{\circ}$ 5.709/71, convalidar os atos praticados na sua vigência, flexibilizar a aquisição de imóveis rurais por estrangeiros e ainda excluir da sua aplicação, como regra, as "pessoas jurídicas brasileiras, ainda que constituídas ou controladas direta ou indiretamente por pessoas privadas, físicas ou jurídicas estrangeiras” ( $\$ 2^{\circ}$, artigo $1^{\circ}$ PL 2.963/19).

As disposições contidas no mencionado projeto de lei resolveriam as discussões acima abordadas, permitiram uma maior previsibilidade do direito, restaurariam a segurança jurídica e, consequentemente, poderia até mesmo atrair mais investimentos para o setor

\footnotetext{
${ }^{4}$ No parecer no AGU/LA-04/94, acolhido pelo parecer GQ-22, a AGU entendeu pela não recepção do $\S 1^{\circ}$, art. $1^{\circ}$ da Lei 5709/71, afastando da aplicação das limitações dessa lei as pessoas jurídicas brasileiras que contam com sócios majoritários estrangeiros. Houve ainda a ratificação desse entendimento no parecer $\mathrm{n}^{\mathrm{o}}$ AGU GQ $181 / 1988$.

${ }^{5}$ No ano de 2008, 14 anos após o primeiro parecer, a AGU emitiu o parecer de no CGU/AGU n. 01/2008 RVJ, passando a entender pela recepção do $\S 1^{\circ}$, art. $1^{\circ}$ da Lei $5709 / 71$. Esse último foi aprovado pelo presidente da República no parecer $\mathbf{n}^{\mathbf{0}} \mathbf{L A} \mathbf{0 1}$ e, por despacho publicado no Diário Oficial da União em 23 de agosto de 2010, vinculou as entidades integrantes da Administração Pública Federal.

${ }^{6}$ Art. 190. A lei regulará e limitará a aquisição ou o arrendamento de propriedade rural por pessoa física ou jurídica estrangeira e estabelecerá os casos que dependerão de autorização do Congresso Nacional. (art. 190, Constituição da República de 1988)
} 
energético. O projeto foi aprovado pelo Senado em 15 de dezembro de 2020, mas aguarda ainda votação na câmara dos Deputados.

\subsection{Contratos em espécie}

Feita a devida contextualização dos contratos de compra e venda e do arrendamento, passa-se ao estudo desses e de outros contratos em espécie utilizados pelos "investidores" e os proprietários das terras rurais usadas para a instalação de usinas de geração de energia fotovoltaica.

O primeiro contrato a ser analisado é a compra e venda, regulada pelo Código Civil de 2002, nos seus artigos 481 a 532. O artigo 481 do Código Civil de 2002 conceitua esse contrato como aquele pelo qual "um dos contratantes se obriga a transferir o domínio de certa coisa, e o outro, a pagar-lhe certo preço em dinheiro". (BRASIL, 2002).

A compra e venda se caracteriza como um contrato translativo, mas que por si só não transfere a propriedade do bem alienado (TARTUCE, 2019, p. 614). Isso porque o modelo brasileiro é o do título e modo, em que os contratos são o título e a causa para o registro respectivo, sendo uma relação de causa e efeito (KUMPEL, 2017, p. 407).

A transmissão da posse de bem móvel somente ocorrerá com a sua tradição ${ }^{8}$, enquanto a transmissão da propriedade de bem imóvel somente ocorre com o registro do título na matrícula do imóvel perante o Ofício de Registro de Imóveis territorialmente competente ${ }^{9}$. Ou seja, o contrato de compra e venda apenas estabelece obrigações entre os contratantes, de forma que o seu descumprimento por qualquer das partes antes da tradição ou do registro, ensejará tão somente perdas e danos, ainda que todo o preço já tenha sido pago (KÜMPEL, 2017, p. 411).

Realmente, a compra e venda de imóvel rural por estrangeiros é regulada no Brasil pela lei $\mathrm{n}^{\circ} 5.709 / 71$, que abrange também as pessoas jurídicas brasileiras que contam com sócios majoritários estrangeiros, sobre as quais há discussão, conforme já explicitado.

Importante destacar que há dois critérios para a definição dos imóveis como rurais. $\mathrm{O}$ primeiro critério é o da destinação, pelo qual é considerado imóvel rural todo aquele que se

\footnotetext{
${ }^{7}$ Lembre-se que o trabalho utiliza o termo "investidores" para fazer menção às pessoas jurídicas que têm como objeto a geração de energia solar e são responsáveis pela implementação das usinas de energia fovoltaica.

${ }^{8}$ Tradição é o termo jurídico utilizado como sinônimo de entrega do bem.

${ }^{9} \mathrm{O}$ artigo 167 da Lei $\mathrm{n}^{\circ}$ 6.015/73 prevê no inciso I um rol taxativo de quais instrumentos podem ser levados a registro no Ofício de Registro de imóveis, e dispõe no item 29) a possibilidade de registro da compra venda pura e da condicional.
} 
“destina à exploração extrativa agrícola, pecuária ou agroindustrial” (art. 4º, I, Lei 4.504/64), independentemente da sua localização. O segundo critério é o da localização, em que o texto constitucional define que são imóveis urbanos aqueles localizados nas áreas do plano diretor ou da lei municipal, conforme o caso, e que, os imóveis rurais, por exclusão, seriam os demais. (KÜMPEL, 2017, p. 409). Segundo KUMPEL (2017, p. 409), o critério da localização parece ser o adotado pelo sistema brasileiro, com base na disposição do artigo 182, parágrafo $1^{\circ}$ da Constituição da República de 1988.

O contrato de compra e venda, no entanto, não é muito utilizado pelos "investidores" na implementação das usinas de geração de energia solar. Isso porque além de ainda haver discussão sobre a situação das pessoas jurídicas que contam com sócios majoritários estrangeiros, esse contrato geralmente onera demasiadamente o projeto.

O segundo contrato a ser estudado é o de arrendamento, que está previsto no Estatuto da Terra, Lei $\mathrm{n}^{\circ} 4.504 / 64$ (BRASIL, 1964), e regulamentado pelo Decreto $\mathrm{n}^{\circ}$ 59.566/66 (BRASIL, 1966). De fato, essa figura contratual busca legitimar a posse daquele que explora a gleba rural sem ser o seu titular dominial.

O contrato de arrendamento rural tem sido muito utilizado na prática pelos “investidores” para formalizar seus negócios jurídicos com os proprietários de terras rurais e viabilizar a implementação das usinas de geração de energia fotovoltaica. No entanto, há muita discussão se esse, realmente, seria o instrumento mais adequado para esses negócios jurídicos.

Como se pode observar, o conceito de arrendamento está previsto no art. $3^{\circ}$ do Decreto 59.566/66, que dispõe o seguinte:

Art. $3^{\circ}$ Arrendamento rural é o contrato agrário pelo qual uma pessoa se obriga a ceder à outra, por tempo determinado ou não, o uso e gozo de imóvel rural, parte ou partes do mesmo, incluindo, ou não, outros bens, benfeitorias e ou facilidades, com o objetivo de nêle [sic] ser exercida atividade de exploracão agrícola, pecuária, agro-industrial, extrativa ou mista, mediante, certa retribuição ou aluguel, observados os limites percentuais da Lei. (BRASIL, 1966). (grifos acrescidos).

Assim como a compra e venda, o arrendamento também deve ser levado a registro para ter publicidade e oponibilidade erga omnes. Por isso, em Minas Gerais, o Provimento Conjunto $n^{\circ} 93$ de 2020, da Corregedoria Geral de Justiça, prevê que nesse caso o registro será feito no Cartório de Registro de Títulos e Documentos e/ou no Registro de Imóveis, a depender das partes envolvidas no negócio jurídico. 
Nesse sentido, no contrato que envolva somente pessoas físicas ou jurídicas de nacionalidade brasileira, o artigo 413, inciso VIII do mencionado Provimento mineiro, prevê que o registro deve ser feito perante Cartório de Registro de Títulos e Documentos da circunscrição do imóvel, para produzir efeitos perante terceiros. Posteriormente, deverá ser averbado na matrícula do imóvel perante o Ofício de Registro de Imóveis competente, conforme artigo 717, inciso XXI do referido Provimento ${ }^{10}$.

Nesse caso, o arrendamento pode ser firmado por instrumento particular e o seu registro e posterior averbação irão garantir a presunção absoluta de publicidade do ato perante terceiros, assim como a sua oponibilidade erga omnes. Com isso, nenhum terceiro interessado no imóvel poderá alegar ter sofrido eventuais prejuízos em razão do não conhecimento do contrato firmado, uma vez que todas as medidas necessárias foram tomadas pelas partes contratantes.

Se, no entanto, o contrato de arrendamento envolver pessoas físicas ou jurídicas estrangeiras, ou ainda, pessoas jurídicas brasileiras que tenham sócio controlador estrangeiro, deverá ser observado o regramento do Provimento $n^{\circ} 43$ da Corregedoria Nacional de Justiça, bem como as restrições estabelecidas pela Lei $n^{\circ} 5.709 / 71$ e pelo seu Decreto Regulamentador $\mathrm{n}^{\mathrm{o}} 74.965$ de 1974.

Nesse sentido, o artigo $1^{\circ}$ do Provimento $n^{\circ} 43$ do CNJ (BRASIL, 2015) dispõe sobre as pessoas que se sujeitam ao regramento específico sobre arrendamento rural, quais sejam:

\footnotetext{
Art. $\mathbf{1}^{\circ}$ Os contratos de arrendamento de imóvel rural serão necessariamente formalizados por escritura pública, quando celebrados por:

I - pessoa física estrangeira residente no Brasil;

II - pessoa jurídica estrangeira autorizada a funcionar no Brasil;

III - pessoa jurídica brasileira da qual participe, a qualquer título, pessoa estrangeira física ou jurídica que resida ou tenha sede no exterior e possua a maioria do capital social. (BRASIL, 2015). (grifos acrescidos).
}

O Provimento $n^{\circ} 43$ do CNJ dispõe no seu artigo $2^{\circ}$ sobre a necessidade de autorização do Instituto Nacional de Colonização e Reforma Agrária - INCRA em determinadas situações ${ }^{11}$ previstas no Decreto $\mathrm{n}^{\circ} 74.965 / 74$.

\footnotetext{
${ }^{10}$ Art. 717. No Ofício de Registro de Imóveis ainda se fará a averbação $[\ldots]$

XXI - do comodato e do arrendamento, desde que previamente registrados no Ofício de Registro de Títulos e Documentos, salvo na hipótese do inciso XXXVII do art. 716, deste Provimento Conjunto; (Provimento Conjunto n 93 de 2020, da Corregedoria Geral de Justiça do Estado de Minas Gerais)

${ }^{11}$ Art. $7^{\circ}$ A aquisição de imóvel rural por pessoa física estrangeira não poderá exceder a 50 (cinqüenta) módulos de exploração indefinida, em área contínua ou descontínua.

$\S 1^{\circ}$ Quando se tratar de imóvel com área não superior a 3 (três) módulos, a aquisição será livre, independendo de qualquer autorização ou licença, ressalvadas as exigências gerais determinadas em lei.
} 
Além das limitações de ordem material impostas pelo Provimento $n^{\circ} 43$, pela Lei $n^{\circ}$ 5.709 de 1971 e pelo Decreto no 74.965/74, há determinadas formalidades adicionais que devem ser observadas pelas partes, Tabeliães de Notas e Oficiais de Registro de Imóveis.

$\mathrm{O}$ artigo primeiro supracitado estabelece que, nesses casos, o contrato de arrendamento rural será necessariamente formalizado por escritura pública, independentemente do valor do imóvel, sendo uma exceção à regra prevista no artigo 108 do Código Civil de $2002^{12}$.

O Provimento $\mathrm{n}^{\mathrm{o}} 43$ determina, ainda, que os tabeliães que lavrarem a escritura pública de arrendamento rural deverão observar “o disposto no art. 23 da Lei no 8.629/1993, bem como os requisitos formais previstos nos artigos 92 e seguintes da Lei ${ }^{\circ}$ 4.504/1964, regulamentada pelo Decreto $n^{\circ}$ 59.566/1966, e o art. 215 do Código Civil de 2002” (BRASIL, 2015). Realmente, foi necessária essa vinculação dos Tabeliães em razão das discussões sobre o $\S 1^{\circ}$, do art. $1^{\circ}$ da Lei $5.709 / 71$ e os pareceres da Advocacia Geral da União, estudados acima.

O Tabelião de notas que vai lavrar a escritura pública é de livre escolha das partes, não podendo, no entanto, praticar atos de seu ofício fora do município para o qual recebeu sua delegação, nos termos dos artigos $8^{\circ}$ e $9^{\circ}$ da Lei no 8.935 de 1994 (BRASIL, 1994).

De qualquer maneira, vale destacar, os Oficiais Registradores de Imóveis deverão informar trimestralmente às suas respectivas Corregedorias Gerais da Justiça e ao INCRA sobre os atos praticados relativos ao "arrendamento de imóvel rural por pessoa constante do art. $1^{\circ}$ do Provimento $n^{\circ} 43$. (BRASIL, 2015, art. $4^{\circ}$ )

Além disso, o registro da escritura pública de arrendamento rural firmado com as pessoas constantes do art. $1^{\circ}$ do Provimento $n^{\circ} 43$ deve ser feito em livro próprio, qual seja, o

$\S 2^{\circ}$ A aquisição de imóvel rural entre 3 (três) e 50 (cinqüenta) módulos de exploração indefinida dependerá de autorização do INCRA, ressalvado o disposto no artigo $2^{\circ}$.

$\S 3^{\circ}$ Dependerá também de autorização a aquisição de mais de um imóvel, com área não superior a três módulos, feita por uma pessoa física.

$\S 4^{\circ} \mathrm{A}$ autorização para aquisição por pessoa física condicionar-se-á, se o imóvel for de área superior a 20 (vinte) módulos, à aprovação do projeto de exploração correspondente.

$\S 5^{\circ} \mathrm{O}$ Presidente da República, ouvido o Conselho de Segurança Nacional, poderá aumentar o limite fixado neste artigo.

${ }^{12}$ Art. 108. Não dispondo a lei em contrário, a escritura pública é essencial à validade dos negócios jurídicos que visem à constituição, transferência, modificação ou renúncia de direitos reais sobre imóveis de valor superior a trinta vezes o maior salário mínimo vigente no País. (BRASIL, 2002) 
"Livro de Registro de Aquisição de Imóveis Rurais por Estrangeiros, na forma prevista no art. 15 do Decreto no 74.965/1974" (BRASIL, 2015, art. 3º).

Em Minas Gerais, o Provimento conjunto n 93 da Corregedoria Geral de Justiça, determina em seu artigo 716, inciso XXXVII, que nesses casos também deverá ser feito o registro prévio do arrendamento no Ofício de Registro de Títulos e Documentos para só então ser possível o seu registo no Cartório de Registro de Imóveis.

Analisadas as regras gerais do arrendamento rural, passa-se ao estudo direcionado para a situação da contratação entre os "investidores" e proprietários das terras rurais usadas para a implementação das usinas geradoras de energia fotovoltaica.

O Colégio Registral Imobiliário de Minas Gerais (CORI), no parecer de nº 001/2018, entendeu que o arrendamento "somente é permitido se a destinação for atividade agropecuária ou agroindustrial" (CORI, 2018, p.3). Com base nessa afirmativa, e partindo do pressuposto de que a atividade de geração de energia solar não se enquadra nesses conceitos, o citado parecer concluiu que o arrendamento não é um contrato apto para ser utilizado no caso em questão e que, portanto, não deverá ter ingresso no Registro de Imóveis.

O entendimento do Colégio Registral, no entanto, retira desse contrato, quando firmado nos casos em estudo, a possibilidade de produzir todos os efeitos que o sistema notarial e registral brasileiro permite. A impossibilidade de registro ou averbação desses contratos, que já são utilizados na prática, impede a sua presunção absoluta de publicidade perante terceiros, a produção de efeitos erga omnes e afeta, assim, a sua segurança jurídica. Com isso, esses contratos terão efeitos somente inter partes.

A utilização do contrato de arrendamento rural entre os "investidores" e proprietários das terras rurais usadas para a instalação das usinas de geração de energia fotovoltaica deve se dar com base em uma interpretação extensiva da norma, de forma a atualizar o instituto e lhe dar maior amplitude e efetividade possíveis.

Ao se fazer uma análise histórica do momento em que o Decreto $n^{\circ} 59.566 / 66$ foi elaborado, percebe-se que ele representa um período eminentemente rural no Brasil. Àquela época não se imaginava o aproveitamento econômico da incidência de luz solar em terras rurais, já que "a primeira usina solar só foi instalada no Brasil em agosto de 2011 [...] no município de Tauá, no sertão do Ceará [...]”. (ÓRIGO. 2020)

$\mathrm{O}$ artigo $1^{\circ}$ do referido decreto estipula que o arrendamento é um contrato agrário que legitima a posse e o uso temporário da terra por aquele que exerça qualquer "atividade 
agrícola, pecuária, agroindustrial, extrativa ou mista”. Seria possível, nos dias atuais, com um pequeno esforço interpretativo, enquadrar a geração de energia solar como atividade extrativa. De fato, a irradiação solar, apesar de ser um recurso inesgotável, é uma fonte de energia limpa e sustentável advinda da natureza, que merece ser valorizada e utilizada sempre que possível, especialmente quando o seu uso permite o abandono da utilização de outras fontes energética poluentes e esgotáveis de energia. E o Direito e a interpretação jurídica não podem desconsiderar isso.

Atualmente o contrato de arrendamento rural é amplamente utilizado na prática entre as concessionárias e permissionárias e o proprietários das terras rurais usadas com a finalidade de implementar as usinas fotovoltaicas. Isso porque se trata de um instituto eminentemente rural, que pressupõe as peculiaridades existentes do campo, e legitima o uso, a posse e a exploração das áreas rurais.

Além disso, esse instrumento contratual possibilita que as partes estipulem regras para a realização dos estudos de viabilidade que geralmente antecedem a instalação das usinas. Esse estudo objetiva analisar o tamanho da área rural disponível, o relevo, o nível de incidência de irradiação solar e outras questões relevantes para o empreendimento. A sua previsão em contrato é essencial para garantir aos "investidores" o acesso às terras privadas para a práticas dos atos necessários antes da instalação das usinas, e o contrato de arrendamento permite que tudo isso aconteça.

Portanto, não obstante o entendimento do Colégio Registral de Minas Gerais, ressalta-se a relevância do contrato de arrendamento para a implementação das usinas de geração de energia solar e que seria ainda mais efetivo se tivesse ingresso no Registro de Imóveis para a produção dos efeitos inerentes aos atos de registro e averbação da matrícula dos imóveis respectivos.

O terceiro contrato a ser analisado é o da locação, pelo qual "uma das partes se obriga a ceder à outra, por tempo determinado ou não, o uso e gozo de coisa não fungível, mediante certa retribuição" (Art. 565, Código Civil de 2002).

As regras gerais da locação estão previstas no Código Civil de 2002, em seus artigos 565 a 578, e têm aplicação residual na omissão das leis específicas. A regulação específica da locação de imóveis, todavia, é regida pela Lei no 8.245 de 1991.

Do conceito de locação expresso acima, extrai-se três elementos essenciais necessários a esse contrato: o tempo, a coisa e a retribuição (GAGLIANO, 2020, p. 652). O 
tempo de duração pode ser por prazo determinado ou indeterminado; a coisa pode ser móvel ou imóvel, devendo sempre ser um bem infungível ${ }^{13}$; e a retribuição, que o caracteriza como contrato oneroso (GAGLIANO, 2020, p. 562-566).

A locação é um contrato típico, uma vez que está previsto expressamente na lei. Além disso, é consensual e não solene "uma vez que se concretiza com a simples declaração de vontade; não exige forma especial, podendo ser convencionado por escrito ou verbalmente" (GAGLIANO, 2020, p. 658).

Quando usado para viabilizar o uso de imóvel rural para instalação de usina de geração de energia fotovoltaica, o instrumento de locação tem ingresso no Cartório de Registro de Imóveis, podendo ter efeitos diferentes a depender do ato a ser praticado pelo Oficial, conforme requerimento das partes. Mas a sua averbação na matrícula do imóvel rural irá conferir presunção de conhecimento (publicidade) por terceiros, bem como irá garantir o direito de preferência ao locatário em caso de alienação do imóvel pelo locador (art. 167, II, 16, Lei $\left.n^{0} 6.015 / 73\right)^{14}$. Além disso, a averbação da locação na matrícula garante a vigência do contrato em caso de alienação da propriedade do bem locado, se houver cláusula com essa previsão (art. 167, I, 3, Lei no 6.015/73) ${ }^{15}$.

Por se tratar de direito obrigacional, o descumprimento do contrato por uma das partes apenas gerará indenização por perdas e danos para o prejudicado. Além disso, o Código Civil prevê a indenização por benfeitorias na coisa locada após o término ou extinção do contrato, havendo também previsão específica sobre o tema nos artigos 35 e 36 da Lei $n^{\circ}$ $8.245 / 91$.

O Colégio Registral de Minas Gerais, ao analisar o uso da locação no parecer $n^{\circ}$ 001/2018, entendeu que "mesmo que seja rural o imóvel onde a usina será implantada, nota-se que a atividade nele exercida não será agropecuária. Isso caracteriza a locação de imóvel

\footnotetext{
${ }^{13}$ Bens infungíveis "são aqueles que não podem se substituídos por outros da mesma espécie, quantidade e qualidade. São também denominados bens personalizados ou individualizados, sendo que os bens imóveis são sempre infungíveis." (TARTUCE, 2019, p. 176)

14 Art. 167 - No Registro de Imóveis, além da matrícula, serão feitos.

II - a averbação: [...]

16) do contrato de locação, para os fins de exercício de direito de preferência.

${ }^{15}$ Art. 167 - No Registro de Imóveis, além da matrícula, serão feitos.

I - o registro: [...]

3) dos contratos de locação de prédios, nos quais tenha sido consignada cláusula de vigência no caso de alienação da coisa locada;
} 
rural, para fins comerciais ou industriais", aplicando-se ao caso a Lei do Inquilinato (Lei $\mathrm{n}^{\circ}$ 8.245/91) (MINAS GERAIS, 2018).

Com isso, o Colégio Registral recomendou a utilização dos contratos de locação nos casos de instalação de usinas de geração de energia fotovoltaica em terras rurais, que terão, portanto, ingresso nos Ofícios de Registros de Imóveis.

Observa-se, no entanto, que a Lei $n^{\circ}$ 8.245/91 dispõe sobre a locação de imóveis urbanos, não legitima a exploração de áreas rurais e sequer aborda situações peculiares aos contratos agrários.

Finalmente, o quarto e último contrato é o direito real de superfície, previsto nos artigos 1.369 a 1.377 do Código Civil de 2002 e nos artigos 21 a 24 da Lei n ${ }^{\circ} 10.257$ de 2001 (Estatuto da Cidade). Há diferenças entre ambos os regramentos, que, no entanto, coexistem no sistema privado nacional. Isso porque o Estatuo da Cidade é lei específica que trata de política de desenvolvimento urbano ${ }^{16}$ (TARTUCE, 2019, p. 979-980).

O artigo 1.369 do Código Civil define o direito de superfície como aquele em que "o proprietário pode conceder a outrem o direito de construir ou de plantar em seu terreno, por tempo determinado, mediante escritura pública devidamente registrada no Cartório de Registro de Imóveis". (BRASIL, 2002).

A constituição desse direito real depende de instrumento público lavrado por Tabelião de Notas e posteriormente registrado no Cartório de Registro de Imóveis ${ }^{17}$ da circunscrição territorial do bem. O registro, nesse caso, é constitutivo e sem ele não há que se falar em direito real.

O parágrafo primeiro do artigo 1.369 do Código Civil dispõe que o "direito de superfície não autoriza obra no subsolo, salvo se for inerente ao objeto da concessão" (BRASIL, 2002). Além disso, a concessão da superfície pode se dar de forma gratuita ou onerosa (GAGLIANO, 2020, p. 1125), e poderá ser transmitida a terceiros pelo superficiário, com direito de preferência ao proprietário do solo.

\footnotetext{
16 “As normas previstas no Código Civil sobre direito de superfície não revogam as relativas a direito de superfície constantes do Estatuto da Cidade (Lei n. 10.257/2001) por ser instrumento de política de desenvolvimento urbano." (Enunciado n ${ }^{\circ} 93$ do CJF/STJ, da I Jornada de Direito Civil)

17 Art. 167 - No Registro de Imóveis, além da matrícula, serão feitos.

I - o registro:

$[\ldots]$

39) da constituição do direito de superfície de imóvel urbano;
} 
A extinção desse direito pode ocorrer pelo esgotamento do prazo (se for determinado), ou ainda se o superficiário der destinação diversa daquela que lhe foi concedida (TARTUCE, 2019, p. 979). Nesse caso, Tartuce (2019) esclarece sobre os efeitos dessa extinção e os direitos do proprietário do solo:

\begin{abstract}
Com a extinção da superfície, o proprietário passa a ter a propriedade plena sobre o terreno, a construção, ou a plantação, as acessões e as benfeitorias, independentemente de indenização, se as partes não estipulares o contrário (art. 1.375 do CC). O comando é específico afastando as normas gerais aplicáveis ao possuidor de boa-fé, como é o caso do superficiário. Consigne-se que a grande vantagem da superfície para o proprietário ou fundieiro é justamente adquirir as construções ou plantações. Como ocorre com a sua constituição, diante do princípio da publicidade, a extinção da superfície deverá ser registrada no Cartório de Registro de Imóveis. (TARTUCE, 2019, p. 979 ).
\end{abstract}

Por outro lado, se o proprietário do solo descumprir o contrato, o superficiário - que no caso em questão são os "investidores" de energia elétrica - poderá continuar exercendo a sua posse até o final do prazo estabelecido. Esse é exatamente o efeito e a grande vantagem de se tratar de um direito real: o imóvel fica vinculado ao cumprimento das obrigações contratuais.

Nesse sentido, o Colégio Registral de Minas Gerais, ao analisar as disposições referentes ao direito real de superfície, concluiu ser um instrumento adequado para a situação específica da instalação das usinas geradoras de energia fotovoltaica e recomendou a sua utilização nesses casos. Com isso, esse direito real terá ingresso no Registro de Imóveis nesses casos, produzindo todos os seus efeitos entre as partes e perante terceiros.

Em conclusão, após o estudo de alguns dos contratos utilizados entre os investidores e os proprietários de terras rurais para a instalação das usinas geradores de energia fotovoltaica, verificou-se que a compra e venda muitas vezes é preterida pelas partes. Já a locação e o direito real de superfície são adequados e aceitos pelos Registradores de Imóveis, tendo ingresso no fólio real. E o arrendamento, apesar das discussões e divergências de entendimentos, parece ser um contrato apto a legitimar esses negócios jurídicos e que merece ter ingresso no fólio real.

\title{
4. CONCLUSÃO
}

A geração de energia solar teve início no Brasil no ano de 2011, sendo uma atividade recente e em rápido crescimento. Com isso, o tema ganha relevância, uma vez que tem atraído 
muitos investimentos para o país. No entanto, as normas não acompanharam o desenvolvimento desse setor, fazendo-se necessário o estudo de alguns de seus aspectos.

A produção centralizada de energia fotovoltaica, é aquela em que uma usina de grande porte é instalada em uma extensa área rural para gerar, transmitir e posteriormente distribuir essa energia. Para isso, é necessário que as pessoas jurídicas geradoras de energia solar contratem com os proprietários das terras rurais. No entanto, não há regulamentação sobre quais contratos podem ser utilizados nesses casos, e é por isso que foi feita uma análise detalhada de cada um dos instrumentos contratuais mais utilizados na prática.

A compra e venda, apesar de em geral ser evitada pelos "investidores" em razão do seu alto custo, é um contrato relevante que, inequivocamente pode ser utilizado nos casos de instalação de usinas de geração de energia fotovoltaica em terras urbanas ou rurais.

Porém, tanto na compra e venda, como no arrendamento rural que envolver pessoas estrangeiras, deverão ser observadas as disposições da Lei no 5.709/71. Em relação às pessoas jurídicas brasileiras com sócios controladores estrangeiros, atualmente estas devem observar a referida lei, mas essa situação pode mudar com o julgamento da Arguição de Descumprimento de Preceito Fundamental n ${ }^{\circ} 342$, ou até mesmo com a aprovação do Projeto de Lei no 2.963/2019.

O contrato de arrendamento rural é amplamente utilizado na prática pelos “investidores" na instalação das usinas de geração de energia fotovoltaica. Mas o Colégio Registral de Minas Gerais, ao proferir o parecer $n^{\circ}$ 001/2018, equivocadamente, afastou a possibilidade de inscrição desses contratos nos Registros de Imóveis nesses casos, impedindo a produção plena dos efeitos de um registro. Defende-se nesta pesquisa, no entanto, a utilização do arrendamento, por ser este um contrato eminentemente rural e que supre as necessidades da situação em questão. Tanto o é, que é um dos contratos mais utilizados na instalação das usinas de geração de energia fotovoltaica instaladas em terras rurais.

Já o contrato de locação, segundo o Colégio Registral de Minas Gerais, e conforme conclusão desta pesquisa, também pode ser estrategicamente utilizado para a instalação de usinas de geração de energia solar em terras rurais, e inscrito nos Registros de Imóveis, com a devida aplicação das normas previstas na lei especial do Inquilinato (Lei no 8.245/91).

Por fim, restou também demonstrada a possibilidade do uso estratégico do direito real de superfície nos casos de instalação de usinas de geração de energia fotovoltaica em terras rurais, pois este instrumento geralmente oferece benefícios a ambas as partes, 
especialmente no eventual inadimplemento do contrato. Isso porque se trata de um direito real em que o imóvel irá garantir o cumprimento das obrigações.

\section{REFERENCIAS}

A história da energia Solar no Brasil. Órigo Energia, 01 Ago 2020. Disponível em: <https://origoenergia.com.br/blog/a-historia-da-energia-solar-nobrasil\#: :text=No\%20entanto\%2C\%20a\%20primeira\%20usina,extremamente $\% 20$ relevante $\%$ 20para\%20a\%20\%C3\%A9poca> Acesso em 15 Jan 2021.

\section{AGÊNCIA NACIONAL DE ENERGIA ELÉTRICA (ANEEL). Informações Técnicas.}

Geração Distribuída. Publicado em 29 Set 2015. Disponível em: <https://www.aneel.gov.br/informacoes-tecnicas/-

lasset_publisher/CegkWaVJWF5E/content/geracao-distribuida-introduc-

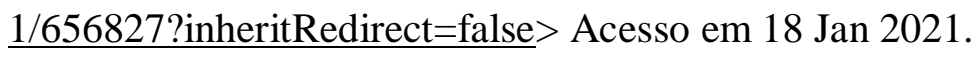

BRASIL. Agência Nacional de Energia Elétrica (ANEEL). Resolução Normativa $\mathbf{n}^{\mathbf{0}} \mathbf{4 8 2}$ de 17 de abril de 2012. Estabelece as condições gerais para o acesso de microgeração e minigeração distribuída aos sistemas de distribuição de energia elétrica, o sistema de compensação de energia elétrica, e dá outras providências. Disponível em: <http://www2.aneel.gov.br/cedoc/ren2012482.pdf> Acesso em 18 Jan 2021.

BRASIL. Conselho da Justiça Federal. Enunciado no 93 da I Jornada de Direito Civil. Coordenador Geral Ministro Ruy Rosado de Aguiar. Comissão de Trabalho Direito das Coisas. Coordenador da Comissão de Trabalho Munir Karam. Disponível em: <https://www.cjf.jus.br/enunciados/enunciado/725> Acesso em 20 Jan 2021.

BRASIL. Corregedoria Nacional de Justiça. Provimento $n^{0} 43$ de 17 de abril de 2015. Dispõe sobre o arrendamento de imóvel rural por estrangeiro residente ou autorizado a funcionar no Brasil, bem como por pessoa jurídica brasileira da qual participe, a qualquer título, pessoa estrangeira física ou jurídica que resida ou tenha sede no exterior e possua a 
maioria do capital social. Disponível em: 〈https://atos.cnj.jus.br/atos/detalhar/2506> Acesso em 16 dez 2020.

BRASIL. Presidência da República. Casa Civil. Subchefia para Assuntos Jurídicos. Constituição da República Federativa do Brasil de 1988. Disponível em: <http://www.planalto.gov.br/ccivil_03/constituicao/constituicao.htm> Acesso em $17 \mathrm{dez}$ 2020.

BRASIL. Presidência da República. Casa Civil. Subchefia para Assuntos Jurídicos. Lei no 4.504 de 30 de novembro de 1964. Dispõe sobre o Estatuto da Terra, e dá outras providências. Disponível em: 〈http://www.planalto.gov.br/ccivil 03/leis/14504.htm> Acesso em 19 Jan 2021.

BRASIL. Presidência da República. Casa Civil. Subchefia para Assuntos Jurídicos. Decreto $n^{\circ} 59.566$ de 14 de novembro de 1966. Regulamenta as Seções I, II e III do Capítulo IV do Título III da Lei $\mathrm{n}^{\circ}$ 4.504, de 30 de novembro de 1964, Estatuto da Terra, o Capítulo III da Lei $\mathrm{n}^{\circ}$ 4.947, de 6 de abril de 1966, e dá outras providências. Disponível em: <http://www.planalto.gov.br/ccivil_03/decreto/antigos/d59566.htm> Acesso em 16 dez 2020.

BRASIL. Presidência da República. Casa Civil. Subchefia para Assuntos Jurídicos. Lei no 5.709 de 7 de outubro de 1971. Regula a Aquisição de Imóvel Rural por Estrangeiro Residente no País ou Pessoa Jurídica Estrangeira Autorizada a Funcionar no Brasil, e dá outras Providências. Disponível em: 〈http://www.planalto.gov.br/ccivil_03/leis/15709.htm> Acesso em 16 dez 2020.

BRASIL. Presidência da República. Casa Civil. Subchefia para Assuntos Jurídicos. Lei n⿳0 6.015, de 31 de dezembro de 1973. Dispõe sobre os registros públicos, e dá outras providências. Disponível em: <http://www.planalto.gov.br/ccivil_03/leis/16015compilada.htm> Acesso em 19 Jan 2021.

BRASIL. Presidência da República. Casa Civil. Subchefia para Assuntos Jurídicos. Decreto $n^{\circ}$ 74.965 de 26 de novembro de 1974. Regulamenta a Lei $n^{\circ}$ 5.709, de 7 de outubro de 1971, 
que dispõe sobre a aquisição de imóvel rural por estrangeiro residente no País ou pessoa jurídica estrangeira autorizada a funcionar no Brasil. Disponível em: <http://www.planalto.gov.br/ccivil_03/decreto/1970-1979/D74965.htm> Acesso em 20 Jan 2021.

BRASIL. Presidência da República. Casa Civil. Subchefia para Assuntos Jurídicos. Lei no 8.245, de 18 de outubro de 1991. Dispõe sobre as locações dos imóveis urbanos e os procedimentos a elas pertinentes. Disponível em: <http://www.planalto.gov.br/ccivil_03/leis/18245.htm> Acesso em 20 Jan 2021.

BRASIL. Presidência da República. Casa Civil. Subchefia para Assuntos Jurídicos. Lei no 8.935, de 18 de novembro de 1994. Regulamenta o art. 236 da Constituição Federal, dispondo sobre serviços notariais e de registro. (Lei dos cartórios). Disponível em: 〈http://www.planalto.gov.br/ccivil_03/leis/18935.htm> Acesso em 19 jan 2021.

BRASIL. Presidência da República. Casa Civil. Subchefia para Assuntos Jurídicos. Lei no 10.406 de 10 de janeiro de 2002. Institui o Código Civil. Disponível em: <http://www.planalto.gov.br/ccivil 03/leis/2002/110406compilada.htm> Acesso em 19 Jan 2021.

F. Ruy. ANEEL Energia Solar: Conheça As Regras Da Autogeração Para Evitar Problemas Com Seu Sistema. Blue Sol Energia Solar, 28 Jun 2019. Disponível em: <https://blog.bluesol.com.br/aneel-energia-solar/> Acesso em 18 Jan 2021.

GAGliANO, Pablo Stolze; FILHO, Rodolfo Pamplona. Manual de Direito Civil. $4^{a}$ ed. São Paulo: Saraiva jur, 2020.

GENTIL. Alberto et al. Registros Públicos. São Paulo: Método, 2020.

KÜMPEL, Vitor Frederico; FERRARI, Carla Modina. Tratado Notarial e Registral. Tabelionato de Notas. Vol 3. 1 $1^{\text {a }}$ ed. São Paulo: YK Editora, 2017. 
MINAS GERAIS. Colégio Registral Imobiliário de Minas Gerais (CORI-MG). PARECER $\mathbf{n}^{\mathbf{0}}$ 001/2018. Parecer jurídico sobre a necessidade de utilização dos instrumentos de locação ou instituição de direito de superfície nos casos de transmissão da posse de imóvel rural para a instalação de usinas de geração de energia fotovoltaica. 2018 Disponível em: < https://corimg.org/files/pareceres/parecer-001-2018.pdf?x36937> Acesso em 10 Jan 2021.

MINAS GERAIS. Corregedoria-Geral de Justiça do Estado de Minas Gerais. Provimento Conjunto $\mathbf{n}^{\mathbf{0}}$ 93/2020. Institui o Código de Normas da Corregedoria-Geral de Justiça do Estado de Minas Gerais, que regulamenta os procedimentos e complementa os atos legislativos e normativos referentes aos serviços notariais e de registro do Estado de Minas Gerais.

<https://www.tjmg.jus.br/data/files/C2/E0/DF/41/B61E27106431D4275ECB08A8/Proviment o\%20Conjunto\%2093-2020.pdf> Acesso em 20 Jan 2021.

TARTUCE, Flávio. Manual de direito civil. Volume único. 9ª ed. São Paulo: Método, 2019. 